BIJ

10,3

246

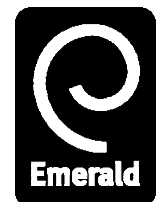

Benchmarking: An International Journal

Vol. 10 No. 3, 2003 pp. 246-260

(1) MCB UP Limited

$1463-5771$

DOI $10.1108 / 14635770310477771$

\section{Outsourcing: guidelines for a structured approach}

\author{
F. Franceschini and M. Galetto
}

Dipartimento di Sistemi di Produzione ed Economia dell'Azienda, Politecnico di Torino, Turin, Italy

A. Pignatelli

Cap Gemini Ernst \& Young Italia, Rome, Italy, and

M. Varetto

Dipartimento di Sistemi di Produzione ed Economia dell'Azienda, Politecnico di Torino, Turin, Italy

Keywords Outsourcing, Quality, Benchmarking, Total quality management, Supplier evaluation

Abstract Outsourcing is a management approach by which an organization delegates some noncore functions to specialized and efficient service providers. In the era of "global market" and "e-economy", outsourcing is one of the main pillars of the new way to conceive the relationships among companies. Despite outsourcing large diffusion, huge business cases and big deals of documentation available on network or press, there is no structured procedure able to support the govern of the evolution of a generic outsourcing process. In accordance with the principles of total quality management, this paper describes a proposal of a new approach for managing outsourcing processes. The model, which can be easily adapted to different application fields, has been conceived with the main aim of managing strategic decisions, economic factors and human resources. The approach is supported by different decision and analysis tools, such as benchmarking techniques, multiple criteria decision aiding (MCDA) methods, cost analysis, and other process-planning methodologies. An application of the method to a real case is also provided.

\section{Introduction}

Outsourcing (from "out" "source", i.e. external source) is a management approach that allows delegating to an external agent operational responsibility for processes or services previously delivered by an enterprise. It can be defined as "... the purchase of a good or a service that was previously provided internally" (Swink, 1999; Smith et al., 1996; Lankford and Parsa, 1999; Elmuti and Kathawala, 2000).

Two of the most important drivers for outsourcing choices are cost efficiency and production reorganization. By outsourcing, companies can focus their efforts on core business, medium-/long-term targets and diversification opportunities (Kippenberger, 1997a, b; Underdown and Talluri, 2002; Linder et al., 2002).

The two main actors of outsourcing processes are the "outsourced" and the "outsourcer" (Saunders and Gebelt, 1997). The first, i.e. the "customer", outsources his processes, while the second, the enterprise, delivers outsourced services (the terms supplier or vendor are also used). The process owner is the 
organizational interface of the two enterprises during all the outsourcing activities (Valentini, 1999).

The last decade showed an evolution in outsourcing processes from traditional to strategic. Outsourcing is considered traditional if a process not considered "critical" for the organization is outsourced. This is the case for activities that do not require specific competencies by the supplier, like canteen services or cleaning services. Strategic outsourcing is "when companies outsource everything except those special activities in which they could achieve a unique competitive edge" (Quinn and Hilmer, 1994; Venka, 1992; Willcocks and Choi, 1995).

The Outsourcing Institute of New York estimated at 85 billion dollars the amount of outsourced business in 1997 in the USA, with an increase of 27 percent compared to 1996 (Dun \& Bradstreet, 1997).

A 1998 Pricewaterhouse Coopers study highlighted that most frequentlyoutsourced processes are related to salaries and taxes calculation, building administration and claims management (Dun \& Bradstreet, 2000). Outsourcing diffusion in the world is not uniform; it is more extended in the USA and in Canada, less in Europe.

A report by Dun \& Bradstreet confirms the trend towards outsourcing, although some companies have shifted their focus from information technology to business process outsourcing (BPO) (Dun \& Bradstreet, 2000).

Actually, despite outsourcing large diffusion, huge business cases and large amounts of electronic or paper documentation, there is a need for a structured procedure able to govern the evolution of a generic outsourcing process (Fagan, 1991; Van Mieghem, 1999; Kakabadse and Kakabadse, 2000; Lonsdale and Cox, 2000; Finizio et al., 2001).

Many authors focus their interest only on some phases of the overall process of outsourcing. In-depth studies have been proposed regarding economical and financial aspects, giving great attention to cost analysis, especially concerning hidden costs and moral hazards (Kippenberger, 1997a, b; Fill and Visser, 2000). In other cases, the problem has been faced from the strategic viewpoint, emphasising risks and advantages which can arise from the practice of outsourcing, and highlighting the importance of contract management (Graham, 1993; Lonsdale, 1999; McIvor, 2000; Udo, 2000; Zhu et al., 2001). In most of cases, the organizational and methodological aspects have been treated (White and James, 1998; Embleton and Wright, 1998; Hines and Rich, 1998; May, 1998; Udo, 2000).

An organization beginning a process of outsourcing should start a benchmarking procedure to evaluate the best practice for its specific case (Yasin, 2002). This paper proposes an integrated model to manage the implementation of an outsourcing process from the "outsourced" point of view. The main aim is organizing all elements that could have impacts on strategic decisions, economic factors, organization and human resources. The model can be easily adapted to specific application fields.
Outsourcing:

a structured

approach 
BIJ

10,3

248

\section{The model}

General description

The model is organized in four main steps (see Figure 1): internal benchmarking analysis, external benchmarking analysis, contract negotiation and outsourcing management; these steps can be further developed in the sequence of Figure 2.

The first step is the internal benchmarking analysis. The "outsourced" monitors his processes, analyzes their efficiency and evaluates what to outsource, considering his core competencies. The external benchmarking analysis regards all the interactions between "outsourced" and "outsourcers", from their selection up to the strategy of relationship management. The outsourcing time evolution is the structured outlet of the method, and the contract negotiation is simply the result of these previous analyses and decisions. The last step is the outsourcing management that consists in the realisation of the planned outsourcing process.

\section{Internal benchmarking analysis}

An organizational change implies the identification of outsourced core competencies, i.e. the set of distinguishing activities in comparison with competitors. The external benchmarking analysis is the considered tool to monitor service levels offered and to define competitors' relative positioning in the market (Karlof and Ostblom, 1993; Hervey and Lush, 1997; Underdown and Talluri, 2002; Yasin, 2002).

The next step is the individualization of the processes to be outsourced. Top management should consider and compare the efficiency of different activities,

Figure 1.

Scheme of a general model for the management of outsourcing processes

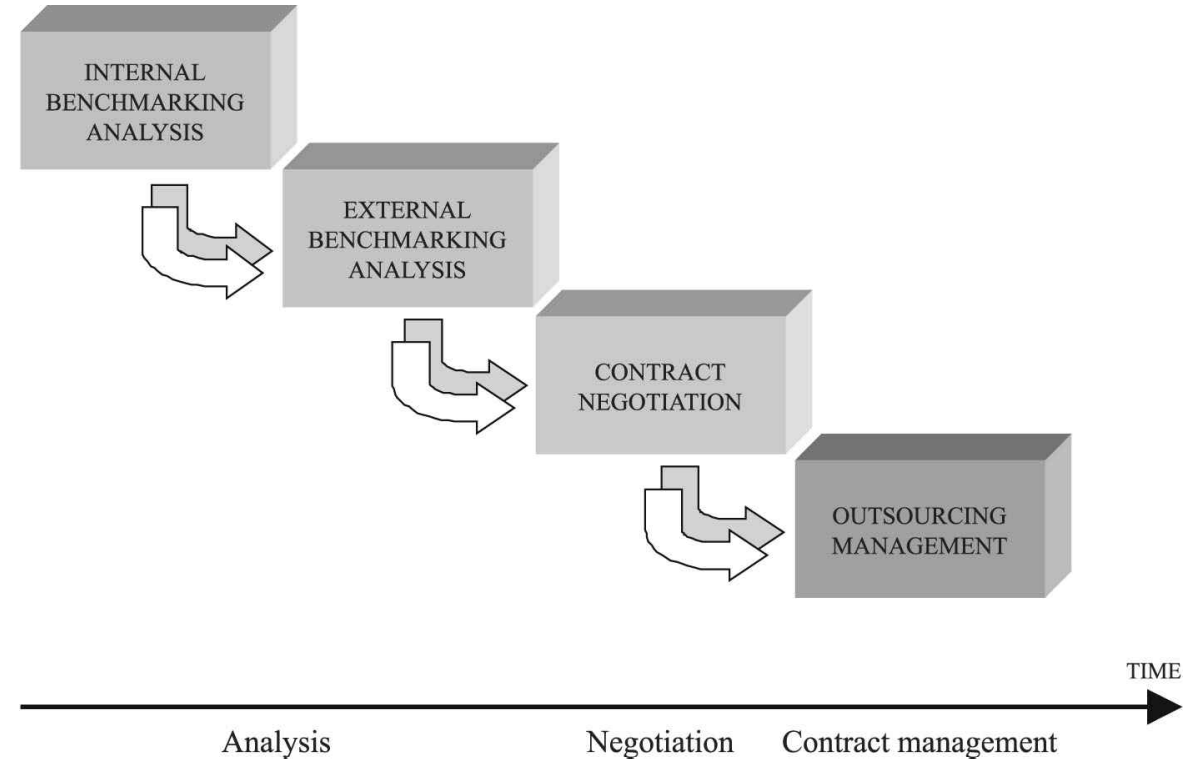




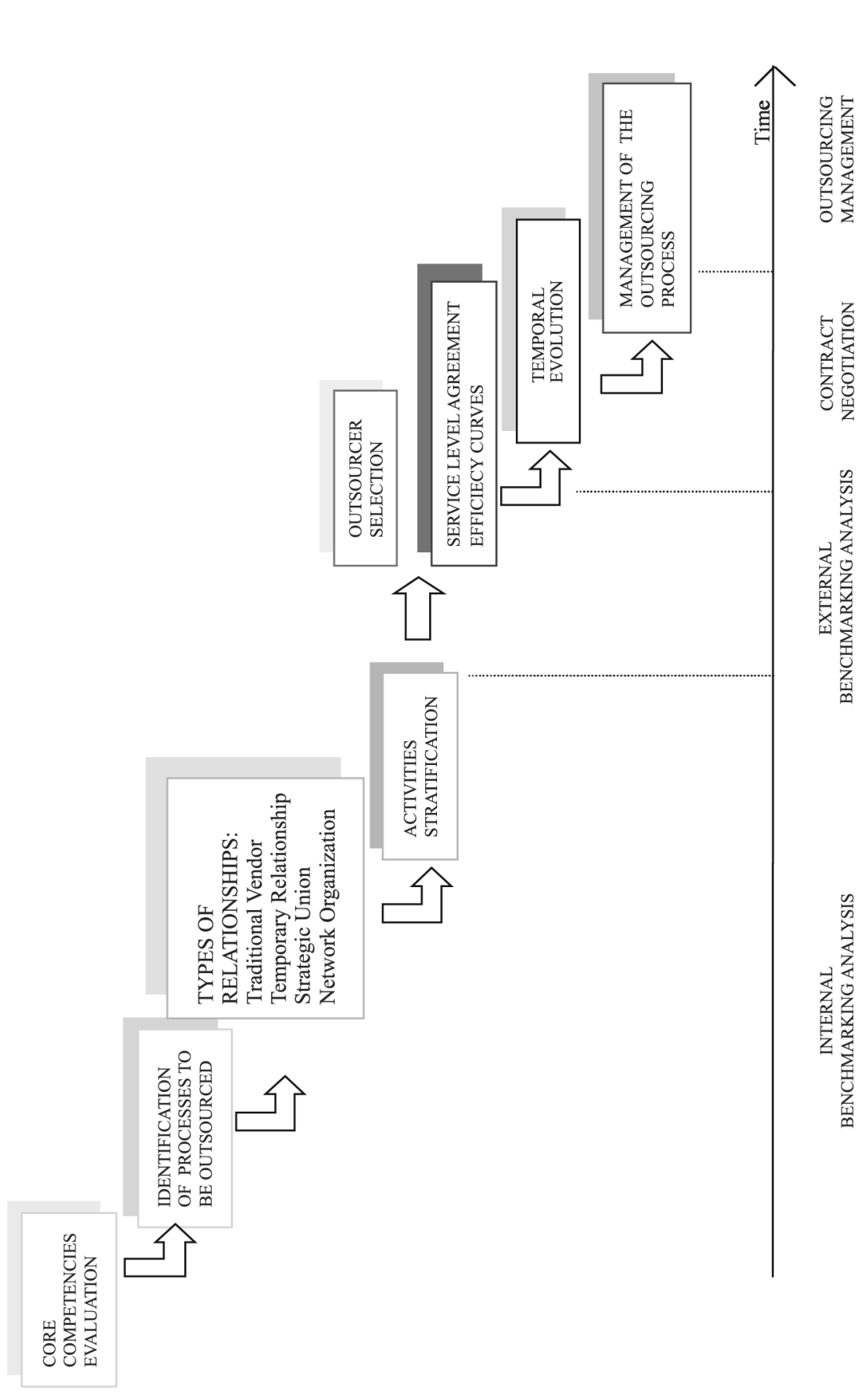

Outsourcing: a structured approach

249

㫐葛

资

Figure 2. Main steps of the proposed model for management of outsourcing processes 
BIJ

10,3

highlighting possible wasting of money and lack of skills. Internal benchmarking, in this case, can be helpful in finding the best practice in each management/production activity and facing the problem of evaluating the corresponding level of efficiency (Kippenberger, 1997a, b; Hyland and Beckett, 2002). Since outsourcing choices are essentially driven by economic factors, then transactional and production costs are relevant in this internal benchmarking analysis (Kippenberger, 1997a, b).

Production costs are directly generated by manufacturing production or service delivery. Usually, outsourcing reduces these costs providing scale economies. An external enterprise, supplying many different customers, can achieve lower prices and better quality service levels.

Transactional costs include all remaining costs:

- Bargaining costs, related to negotiation between parties during contract definition.

- Monitoring costs.

- Contractual opportunism costs, due to the general opportunistic behavior of a contractor during preliminary phases. These aspects, as moral hazards, are frequent in outsourcing relationships because it is not easy to monitor a supplier's real work or diligence (Ngwenyama and Bryson, 1999; Frost, 2000).

- Market costs, related to the presence of a limited number of suppliers. In this context, the "outsourced" has a weak contractual power, especially in renewal or renegotiations of a new contract. When the market offers a great number of suppliers, the "outsourced" will usually select the less expensive one. This vendor will earn a competitive advantage over the competitors due to a bigger knowledge of the "end client", and here opportunism could intervene (Aubert et al., 1996).

- Costs related to managers, who try to obstruct the outsourcing process. Choices are not only the result of a cost- or a strategic analysis; they are also influenced by power and political tactics of managers (Lacity and Hirscheim, 1993).

Types of relationships between "outsourced" and "outsourcer". Many different types of outsourcing relationships may be considered (Downey, 1995). To analyze them, we investigate two main characteristics: "specificity" and "complexity". "Specificity" refers to the level of reutilization of the considered goods/process for many different uses. "Specificity" can depend on physical location or unique skills in terms of resources and techniques. Outsourcing relationships of processes that need specific assets can cause hidden costs (Kippenberger, 1997a, b). Usually, they do not allow different uses (Van Mieghem, 1999).

"Complexity" refers to the difficulty of monitoring and defining contract terms and conditions of the outsourcing process (Vining and Globerman, 1999). 
Two levels of evaluation, low and high, define each characteristic. The combination of the two characteristics gives rise to four types of relationships:

(1) traditional vendor;

(2) temporary relationship;

(3) strategic union; and

(4) network organization (see Figure 3).

A detailed map of the main characteristics of "outsourced"-"outsourcer" relationships is reported in Table $\mathrm{I}$.

Activities stratification. As shown in Figure 4, the model is able to suggest a concentric stratification of the activities to be outsourced. According to the model, all these activities are arranged within specific layers.

The ordered activities will be outsourced according to progressive "layers". This stratification can be obtained by an evaluation of the following criteria:

- "Outsourced" technical competency: involved in the implementation of the outsourcing process. This reflects the capability of the "outsourced" in managing the transition to the new organization system.

- Total buying cost: sum of supplier production and management costs.

- End-user involvement: represents the level of interaction between the "outsourcer" and the end user. For example, a back-office process has a more minor impact on the end user than other activities, such as public relations.

- Core business dependencies: an activity to be outsourced is considered more important if it is nearer to the organization's core business.

- Safety of involved people or machines in the outsourcing process.

- Reservedness: guarantees the security of confidential information.

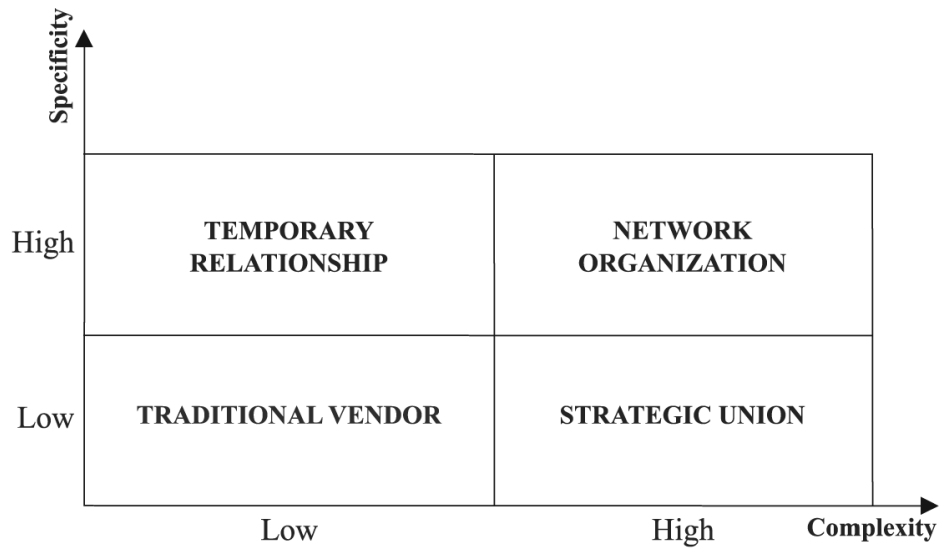

Figure 3. Scheme of the four types of outsourced-outsourcer relationships based on different levels of complexity and specificity 
BIJ

10,3

252

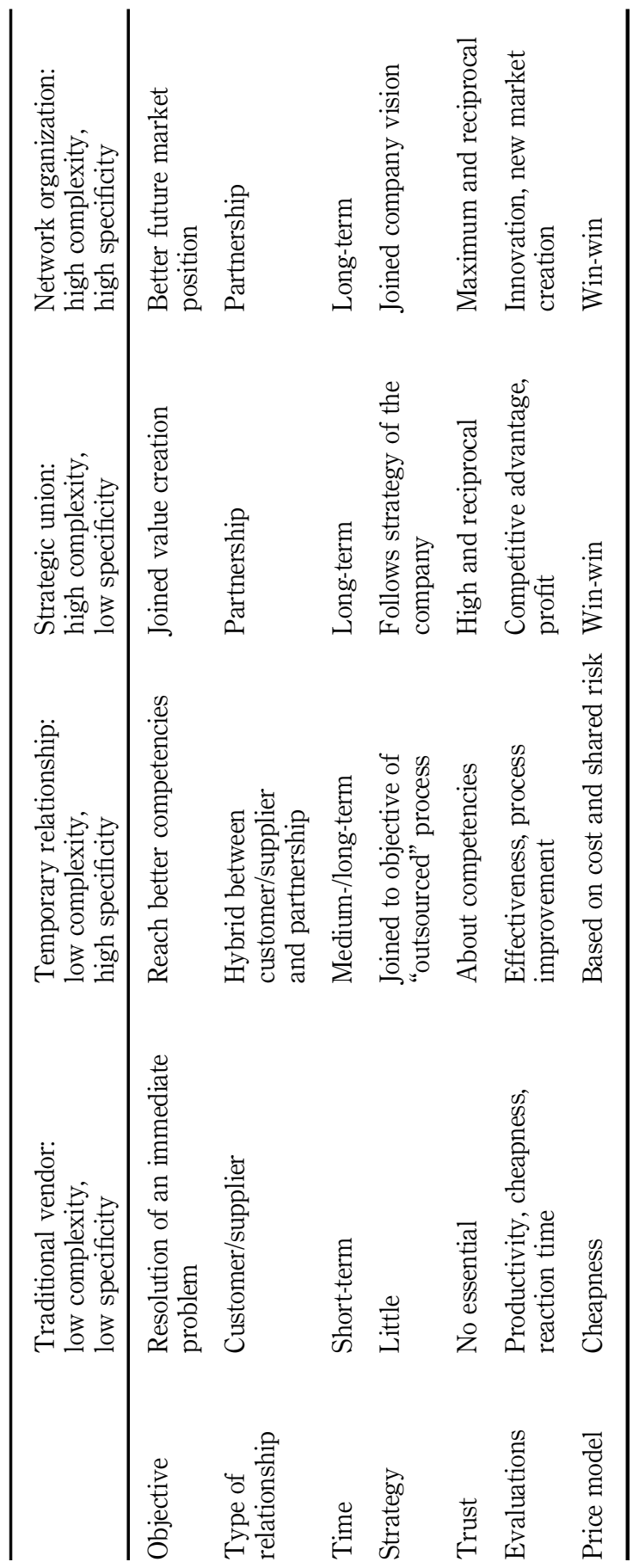

Table I.

Main characteristics of different types of outsourcedoutsourcer relationships 
- Monitoring process: refers to easiness of activity control.

- Internal human resources: skills and know-how.

The ordering of activities for the activation of an outsourcing process is a critical point. The conditions that can influence activities' ranking are the degree of significance of each single criterion and the "strength" of the arguments required for validating the judgement that one activity is more "strategic" than another.

These issues are well dealt with by means of multiple criteria decision aiding (MCDA) methods. The element at the basis of MCDA is the outranking concept. An outranking relation is a model to aggregate and synthesize the evaluations of a set of alternatives by a set of $n$ criteria. The hypotheses required to implement MCDA are less restrictive than those required by the utility theory (Fishburn, 1970; Ostanello, 1985; Roy, 1991).

The implementation of MCDA methods requires the construction of a "relationship matrix" (see Table II). To join criteria and alternatives (the

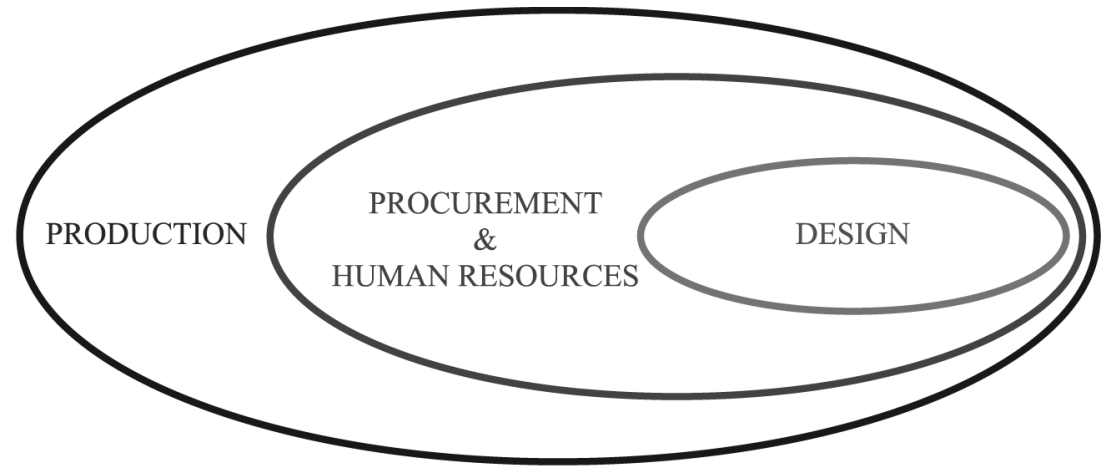

Outsourcing: a structured approach

253

Figure 4. Example of a concentric stratification obtained with the data in Table II (the more external activities are selected to be outsourced first)

Activities

Human

Criteria

Weights

Design Production

Procurement

resources

Technical skills

Total cost for a process/service

Involvement of customer

Core business closeness

Safety

Reservedness

Easiness to monitor outsourcer performance

Internal human resources

Note: The following symbolism is used: $X$ for a strong relationship, $O$ for a medium one and $\Delta$ for a weak one. If there is no relationship, an empty cell is shown
Table II.

Example of a relationship matrix for the evaluation of activities involved in an outsourcing process 
BIJ

10,3 activities to be outsourced) the following symbolism may be used: $X$ for a strong relationship, $O$ for a medium one and $\Delta$ for a weak one. If there is no relationship an empty cell is shown. The decision maker may also define different levels of importance for each criterion (weights).

The output of a MCDA method is a ranking of activities to be potentially outsourced (concentric stratification, see Figure 4).

\section{External benchmarking analysis}

Outsourcer evaluation. The aim of the external benchmarking analysis is supplier selection. The "outsourced" can choose to cooperate with a single "outsourcer", more independent suppliers or different "outsourcers" coordinated by a single vendor leader. Relevant strategies are single vendor, multiple vendors or integrated suppliers:

- Single vendor (single "outsourcer"). The two organizations ("outsourced" and "outsourcer") work together, the vendor understands client needs and offers better services. The weakness of this strategy is the "loss" of a "best-of-breed" performance.

- Multiple vendors (more suppliers managed by the "outsourced"). This strategy implies a significant effort to monitor and co-ordinate more vendors; however, it allows better services and lower costs.

- Integrated suppliers (more suppliers managed by a single "outsourcer"). This approach presents the same advantages as the two previous ones. The "outsourced" has less co-ordination problems; he interacts only with main outsourcer, responsible for the performance of all suppliers.

The best strategy is selected again by a MCDA method. Selection criteria are the following: market positioning, price, technical quality, ability to manage "outsourced"-"outsourcer" relationships, and possible previous contracts.

SLA and efficiency curves. In this section, we face the problem of designing outsourcing relationships and their targets. First of all, the "outsourced" defines the service levels of the process, the so-called service level agreement (SLA). The SLA is a commitment between process owners and the respective teams, included in the contract. In the big companies, the service level management (SLM) completes this task. It consists of a group of experts that monitors, controls and evaluates service levels and manages supplier relationships.

The evolution of suppliers' performance can be performed by the so-called efficiency curves. For each SLA index, we define two curves: the first draws targets to achieve; the second describes the outsourcing process performance during the implementation phase.

For each phase we suggest a two-axis representation: the time axis shows scheduled controls and check moments established by the parties. For each SLA index, an ideal curve with foreseen and effective values is drawn. From these graphs we are able to study the gaps between the two curves over time. 
When targets are reached, new activities can be outsourced. Figure 5 shows efficiency curves for a SLA index in a two-phases process. Efficiency curves allow the representation of trends of performance, budget and realized values in terms of time, money, and people. Curves for different SLAs may be parallelly developed.

Outsourcing: a structured approach

\section{Contract negotiation}

The contract development step, as in Figure 2, is the formalization of the relationship between "outsourced" and "outsourcer". We do not mean that an outsourcing process is successful if everything is "crystallized" in a contract. Nevertheless, it is important to formalize the kind of relationship, its time development, the expected targets, the criteria of evaluation to be utilized, and the way to address any controversy (Graham, 1993).

\section{Managing outsourcing process}

Time evolution. Targets and check moments are jointly defined by "outsourced" and "outsourcer". For managing the time evolution of an outsourcing process it is necessary to fix performance levels for SLA indexes, check moments and tolerated gaps between objective and realized curves. If tolerated gaps are exceeded, the outsourced analyzes the reasons and provides corrective actions.

A reason for exceeding foreseen gaps could be the incorrect definition of SLA values or check moments to achieve them. Bad performance could also depend on activities' arrangement in progressive layers (as discussed earlier). If none of these causes is the reason for the exceeded gaps, the "outsourced" should reconsider his strategy and think about re-insourcing the process (backsourcing), i.e. re-conduct activities again within the organization.

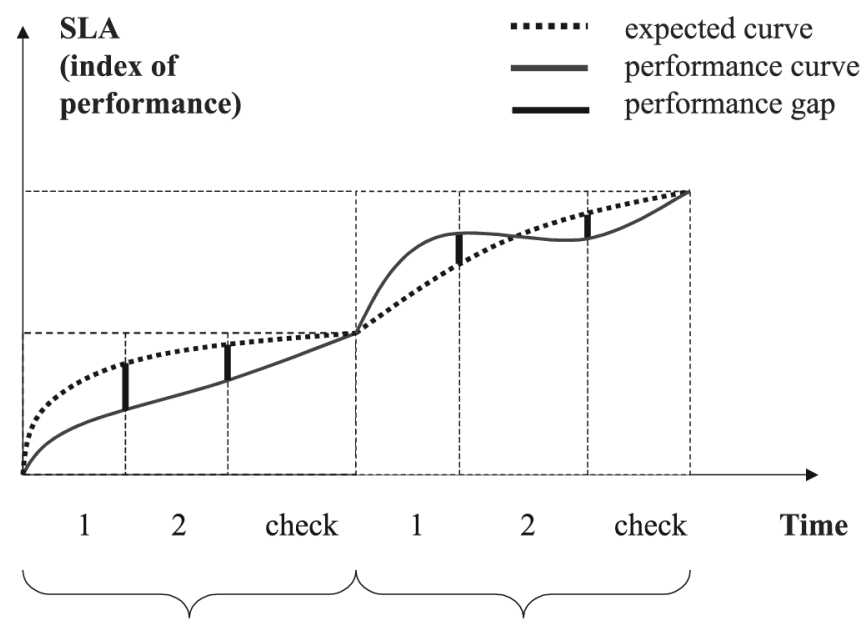

Figure 5. Diagram of "efficiency curves" for a two-phase process. Each control highlights the gaps between expected and Phase $1 \quad$ Phase 2 performance curves 
BIJ

10,3

256
The "test bench". The method introduced here for the management of outsourcing processes can be applied by following a series of structured steps. In order to analyze the situation at hand in every single phase of the process, each step is organized to operate in the most effective way.

This "step-by-step" approach can also be employed as a kind of "test bench" for the evaluation of different strategies in the management of outsourcing processes.

The test bench has a general structure (see Figure 6) which can be articulated as follows:

(1) definition of the phase of the outsourcing process to be implemented;

(2) collection and evaluation of all the possible information about the outsourcing process;

\section{START OF A NEW PHASE IN THE OUTSOURCING PROCESS}

Is there necessary information to implement the proposed method?

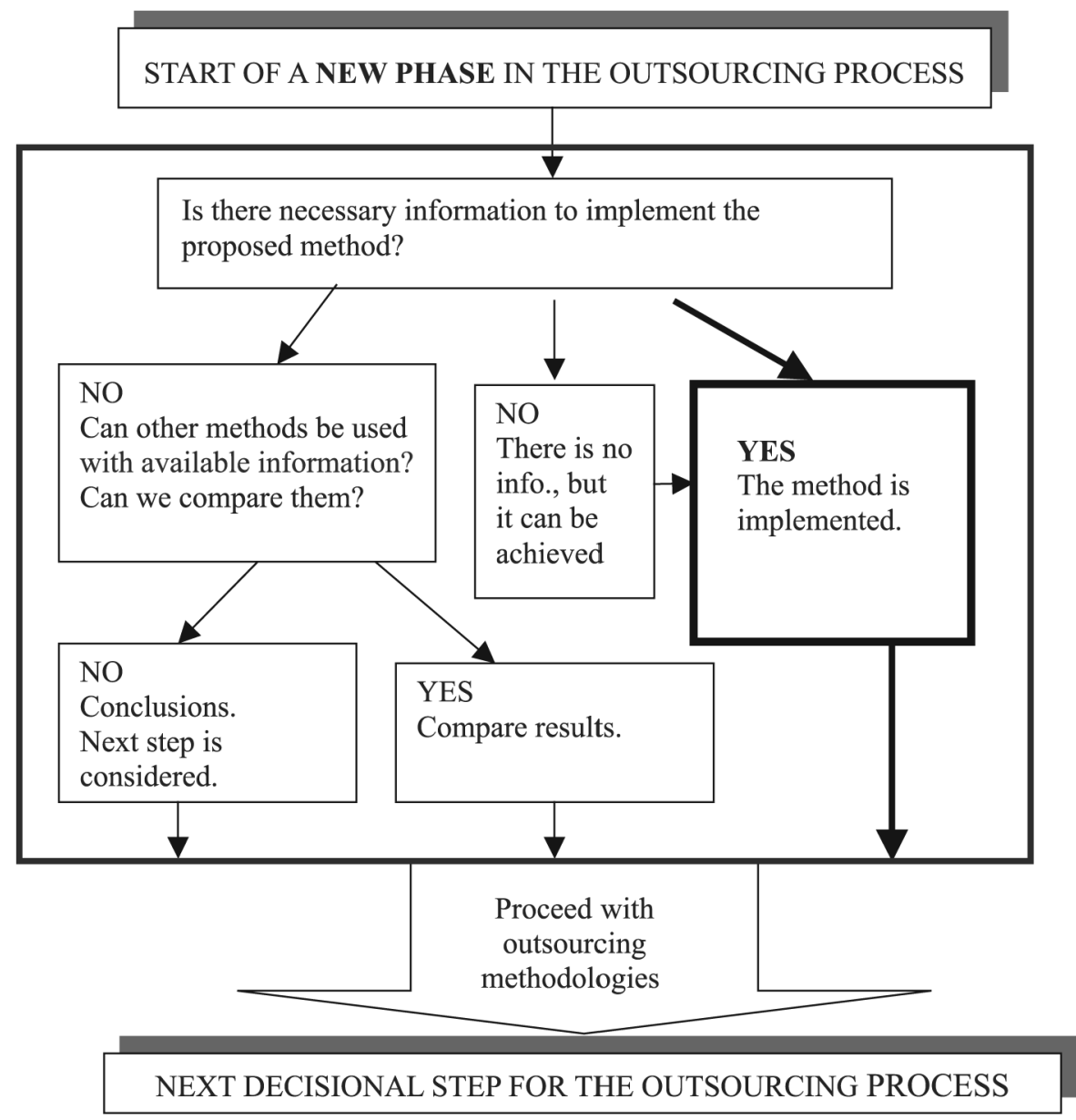

NEXT DECISIONAL STEP FOR THE OUTSOURCING PROCESS
Figure 6.

Example of the general structure of the "test bench" (see text for details of how the tool is structured) 
(3) application of the proposed method and study of other possible alternatives;

(4) analysis of results; and

(5) next phase.

Outsourcing:

a structured

approach

This procedure can be easily implemented as a software tool to guide "outsourced" choices during the evolution of the entire outsourcing process.

A case study. The test-bench tool has been applied to the outsourcing of the information technology department of an international automotive company. The contingency of the case has allowed a complete application of the method during all the phases of the outsourcing process (Cap Gemini Ernst \& Young Italia, 2000).

The implemented procedure presents a conceptual structure very similar to the one described in Figure 2. Every phase faces an aspect of the outsourcing process and defines the possible actions the "outsourced" should achieve.

From the detailed analysis of the sector to be outsourced, three major activities have been defined: the information technology (IT) management; the help-desk service; and the on-site services for the monitoring and resolution of information-system problems. These activities have been outsourced in this specific order, defined by means of the described stratification technique (as discussed earlier).

For each activity, as a result of a benchmarking analysis with other similar services, the SLA targets have been defined. For example, referring to the helpdesk service, we defined three priority levels, and, for each of them we fixed the maximum lead time for the resolution of the relative problems, and the percentage of solved questions into the defined time limit. The obtained values for the first four months of activity in the new "outsourced" arrangement are reported in Table III.

The application of the described methodology to the outsourcing process of the IT department has achieved two remarkable results:

(1) a growth of a more conscious vision and utilisation of the IT resources;

(2) the introduction of a rationalised methodology for supplier selection, and the application of a structured approach for performance evaluation.

Furthermore, the proposed approach has also led to the solving of the problem of managing a domain technologically separated from the core activities of the company.

\section{Conclusions}

The aim of this paper is to present a general model able to analyze and drive an outsourcing process throughout all decisional steps. The main innovation of the proposed approach is a dynamical vision of the outsourcing problem, which permits the taking control of and redesigning of the targets of outsourcing during the evolution time of the process. The method is also able to stimulate 
BIJ

10,3

Table III.

SLA indexes for behavior for the help-desk service described in the reported case study

\begin{tabular}{|c|c|c|c|c|}
\hline & & $\begin{array}{l}\text { Priority } 1 \\
\qquad \begin{array}{l}8 \\
93\end{array}\end{array}$ & $\begin{array}{l}\text { Priority } 2 \\
\text { Maximum lead time (h) } \\
20 \\
\text { Fixed percentage } \\
88\end{array}$ & $\begin{array}{l}\text { Priority } 3 \\
32 \\
80\end{array}$ \\
\hline 1 month & $\begin{array}{l}\text { Obtained values }(\%) \\
\text { SLA satisfaction }\end{array}$ & $\begin{array}{l}100 \\
\text { Yes }\end{array}$ & $\begin{array}{l}98 \\
\text { Yes }\end{array}$ & $\begin{array}{r}0 \\
\text { No }\end{array}$ \\
\hline 2 month & $\begin{array}{l}\text { Obtained values (\%) } \\
\text { SLA satisfaction }\end{array}$ & $\begin{array}{l}100 \\
\text { Yes }\end{array}$ & $\begin{array}{l}89.4 \\
\text { Yes }\end{array}$ & $\begin{array}{l}66 \\
\text { No }\end{array}$ \\
\hline 3 month & $\begin{array}{l}\text { Obtained values (\%) } \\
\text { SLA satisfaction }\end{array}$ & Not appl. & $\begin{array}{l}92.7 \\
\text { Yes }\end{array}$ & Not appl. \\
\hline 4 month & $\begin{array}{l}\text { Obtained values }(\%) \\
\text { SLA satisfaction }\end{array}$ & $\begin{array}{c}- \\
\text { Not appl. }\end{array}$ & $\begin{array}{l}94.2 \\
\text { Yes }\end{array}$ & $\begin{array}{l}100 \\
\text { Yes }\end{array}$ \\
\hline \multicolumn{5}{|c|}{$\begin{array}{l}\text { Note: For each period, three priority levels have been defined. The maximum lead time for } \\
\text { problem resolution and the percentage of questions to be solved within defined time limits have } \\
\text { been provided. In some periods, the index has not been calculated because of the lack of calls } \\
\text { Source: Cap Gemini Ernst \& Young Italia (2000) }\end{array}$} \\
\hline
\end{tabular}

the "outsourced" to dedicate more effort towards the analysis of organizational aspects and towards processes definition.

The study highlights the need for a structured benchmarking theory and best practices in outsourcing. The described methodology tries to fill in in the gap still existing between the common practices and a best-structured approach.

Outsourcing can be an excellent way to improve processes, but at the same time, if improperly used, it might lead companies to loose their skills and knowledge, which are difficult to recover.

From the analysis of the case study, it is possible to assess the advantages that an organization can achieve by applying a structured approach to outsourcing. In particular, the results obtained by the case study highlight a more conscious vision and utilisation of the IT resources, the introduction of a rationalised methodology for supplier selection, and the application of a structured performance evaluation.

Future developments of the method will be dedicated to further application of the "test bench" to other practical cases, in order to validate the efficiency of the methodology in different situations, as well as to the study of a similar procedure to manage the reverse problem of backsourcing.

\section{References}

Aubert, B., Rivard, S. and Patry, M. (1996), “A transaction cost approach to outsourcing behavior: some empirical evidence”, Information \& Management, Vol. 30, pp. 51-64.

Cap Gemini Ernst \& Young Italia (2000), RVI Executive-Summary, 2 October (internal report).

Downey, J.M. (1995), "Risk of outsourcing - applying risk management techniques to staffing methods”, Facilities, Vol. 13 No. 9, pp. 38-44. 
Dun \& Bradstreet (1997), The Outsourcing Index, The Outsourcing Institute, December, New York, NY.

Dun \& Bradstreet (2000), The Outsourcing Index, The Outsourcing Institute, December, New York, NY.

Elmuti, D. and Kathawala, Y. (2000), "The effects of global outsourcing strategies on participants' attitudes and organizational effectiveness", International Journal of Manpower, Vol. 21 No. 2, pp. 112-28.

Embleton, P.R. and Wright, P.C. (1998), "A practical guide to successful outsourcing", Empowerment in Organizations, Vol. 6 No. 3, pp. 94-106.

Fagan, L. (1991), “A guide to global sourcing”, The Journal of Business Strategy, Vol. 2, pp. 21-5.

Fill, C. and Visser, E. (2000), "The outsourcing dilemma: a composite approach to the make or buy decision”, Management Decision, Vol. 38 No. 1, pp. 43-50.

Finizio, C., Franceschini, F., Galetto, M. and Iancale, R. (2001), "Qualità nei servizi e outsourcing: un'applicazione nel settore della Difesa”, De Qualitate, April, pp. 25-35.

Fishburn, P.C. (1970), Utility Theory for Decision Making, Wiley, New York, NY.

Graham, R. (1993), "Outsourcing and keeping control: the key legal issues", Property Management, Vol. 11 No. 2.

Frost, C. (2000), “Outsourcing or increasing risks?”, Balance Sheet, Vol. 8 No. 2, pp. 34-7.

Hervey, M. and Lush, R. (1997), "Protecting the core competencies of a company: intangible asset security”, European Management Journal, Vol. 15 No. 4, pp. 370-80.

Hines, P. and Rich, N. (1998), "Outsourcing competitive advantage: the use of supplier associations", International Journal of Physical Distribution \& Logistics Management, Vol. 28 No. 7, pp. 524-46.

Hyland, P. and Beckett, R. (2002), "Learning to compete: the value of internal benchmarking", Benchmarking: An International Journal, Vol. 9 No. 3, pp. 293-304.

Kakabadse, N. and Kakabadse, A. (2000), "Critical review - outsourcing: a paradigm shift”, The Journal of Management Development, Vol. 19 No. 8, pp. 670-728.

Karlof, B. and Ostblom, S. (1993), Benchmarking: A Signpost to Excellence in Quality and Productivity, Wiley, New York, NY.

Kippenberger, T. (1997a), "Part 1. Outsourcing: how close to the core can you go?", The Antidote, Vol. 2 No. 6, pp. 20-1.

Kippenberger, T. (1997b), "Part 2. Some hidden costs of outsourcing", The Antidote, Vol. 2 No. 6, pp. 22-3.

Lacity, M. and Hirscheim, R. (1993), “The information systems outsourcing bandwagon”, Sloan Management Review, pp. 73-86.

Lankford, W.M. and Parsa, F. (1999), “Outsourcing: a primer”, Management Decision, Vol. 37 No. 4, pp. 310-6.

Linder, J.C., Cole, M.I. and Jacobson, A.L. (2002), "Business transformation through outsourcing”, Strategy and Leadership, Vol. 30 No. 4, pp. 23-8.

Lonsdale, C. (1999), "Effectively managing vertical supply relationships: a risk management model for outsourcing”, Supply Chain Management: An International Journal, Vol. 4 No. 4, pp. 176-83.

Lonsdale, C. and Cox, A. (2000), “The historical development of outsourcing: the latest fad?", Industrial Management \& Data Systems, Vol. 100 No. 9, pp. 444-50.
Outsourcing: a structured approach 
BIJ

10,3

260
McIvor, R. (2000), "A practical framework for understanding the outsourcing process", Supply Chain Management: An International Journal, Vol. 5 No. 1, pp. 22-36.

May, A.S. (1998), "Business process outsourcing: a new test of management competence", Career Development International, Vol. 3 No. 4, pp. 136-41.

Ngwenyama, O. and Bryson, N. (1999), "Making the information systems outsourcing decision: a transaction cost approach to analysing outsourcing decision problems", European Journal of Operational Research, Vol. 115, pp. 351-67.

Ostanello, A. (1985), "Outranking methods”, in Fandel, G. and Spronk, J. (Eds), Multiple Criteria Decision Methods and Application, Springer-Verlag, Berlin, pp. 41-60.

Quinn, J. and Hilmer, F. (1994), "Strategic outsourcing”, Sloan Management Review, pp. 43-55.

Roy, B. (1991), "The outraking approach and the foundations of electre methods”, Theory and Decision, Vol. 31 No. 1, pp. 49-73.

Saunders, C. and Gebelt, M. (1997), "Achieving success in information systems outsourcing”, California Management Review, Vol. 39 No. 2, pp. 63-77.

Smith, A., Mitra, S. and Narasimhan, S. (1996), "Offshore outsourcing of software development and maintenance: a framework for issues”, Information \& Management, Vol. 31, pp. $165-75$.

Swink, M. (1999), "Threats to new product manufacturability and the effects of development team integration processes", Journal of Operations Management No. 17, pp. 691-709.

Udo, G.G. (2000), "Using analytic hierarchy process to analyze the information technology outsourcing decision”, Industrial Management \& Data Systems, Vol. 100 No. 9, pp. 421-9.

Underdown, R. and Talluri, S. (2002), "Cycle of success: a strategy for becoming agile through benchmarking”, Benchmarking: An International Journal, Vol. 9 No. 3, pp. 278-92.

Valentini, S. (1999), Gestire L'outsourcing, i Passi Fondamentali per Avere Successo in un Processo di Ristrutturazione, Franco Angeli, Milan.

Van Mieghem, J. (1999), “Co-ordinating investment, production, and subcontracting”, Management Science, Vol. 45 No. 7, pp. 954-71.

Venka, T.R. (1992), "Strategic sourcing: to make or not to make", Harvard Business Review, pp. 1-11.

Vining, A. and Globerman, S. (1999), "A conceptual framework for understanding the outsourcing decision”, European Management Journal, Vol. 17 No. 6, pp. 645-54.

White, R. and James, B. (1998), The Outsourcing Manual, Ashgate Publishing Company, Aldershot.

Willcocks, L. and Choi, C.J. (1995), "Co-operative partnership and total IT outsourcing: from contractual obligation to strategic alliance”, European Management Journal, Vol. 13 No. 1, pp. 67-78.

Yasin, M.M. (2002), "The theory and practice of benchmarking: then and now", Benchmarking: An International Journal, Vol. 9 No. 3, pp. 217-43.

Zhu, Z., Hsu, K. and Lillie, J. (2001), "Outsourcing - a strategic move: the process and the ingredients for success”, Management Decision, Vol. 39 No. 5, pp. 373-8. 